\title{
Association of oncogenic bacteria with colorectal cancer in South China
}

\author{
Youlian Zhou ${ }^{1}$, Hanchang $\mathrm{He}^{2}$, Haoming $\mathrm{Xu}^{1}$, Yingfei $\mathrm{Li}^{1}$, Zhiming $\mathrm{Li}^{1}$, Yanlei $\mathrm{Du}^{1}$, \\ Jie $\mathrm{He}^{1}$, Yongjian Zhou ${ }^{1}$, Hong Wang ${ }^{1}$, Yuqiang Nie ${ }^{1}$ \\ ${ }^{1}$ Department of Gastroenterology, Guangzhou Digestive Disease Center, Guangzhou First People's Hospital, Guangzhou \\ Medical University, Guangzhou, 510180, China \\ ${ }^{2}$ The First People's Foshan Hospital, Chancheng District, Foshan, 528000, Guangdong, China
}

Correspondence to: Yuqiang Nie, email: nieyq@medmail.com.cn

Keywords: colorectal cancer, fusobacterium spp., enterococcus faecalis, enterotoxigenic bacteroidesfragilis, enteropathogenic escherichia coli

Received: June 29, 2016

Accepted: October 28, 2016

Published: November 04, 2016

\section{ABSTRACT}

To quantify Fusobacterium spp., Enterococcus faecalis (E.faecalis), Enterotoxigenic Bacteroides fragilis (ETBF), and Enteropathogenic Escherichia coli in colorectal cancer (CRC) patients and their possible association with CRC clinicopathogical features, we collected the resected tumors and adjacent normal tissues (N) from 97 CRC patients. 48 age- and sex-matched healthy controls (HC) were also recruited. Real-time PCR was used for bacterial quantification. The median abundance of Fusobacterium spp. ( $p<0.001$, vs. $N$; $p<0.01$,vs. HC), E.faecalis ( $p<0.05$, vs. $N$; $p<0.01$, vs. HC) and ETBF ( $p<0.001$, vs. N; $p<0.05$, vs. HC) in tumor tissues was significantly higher than that detected in normal tissue and HC. E.faecalis was detected in $\mathbf{9 5 . 8 8 \%}$ of tumors and $\mathbf{9 3 . 8 1 \%}$ of adjacent tissues. Fusobacterium spp. was detected in $72.16 \%$ of tumors and $67.01 \%$ of adjacent tissues. The combined E.faecalis and Fusobacterium spp. were detected in $\mathbf{7 0 . 1 0} \%$ of tumors and $\mathbf{3 6 . 0 8 \%}$ of adjacent normal tissues. All four bacteria were detected in $33.72 \%$ and $22.09 \%$ of paired tumor and adjacent normal tissues, respectively. E.faecalis and Fusobacterium spp. are enriched in both tumor and adjacent tissue of CRC patients when compared to HC, suggesting that it is possible to be previously undetected changes in the pathohistologically normal colon tissue in the proximity of the tumor.

\section{INTRODUCTION}

Many studies have established a causal link between bacterial and viral infections and cancers like for instance the link between Human papilloma virus and cervical cancer [1], H.pylori and gastric carcinoma [2], Hepatitis B and $\mathrm{C}$ virus and hepatocellular carcinoma $[3,4]$. Colorectal cancer is one of the most common types of cancer and the third cause of cancer mortality worldwide [5]. Its etiology is still not fully understood. The possible influence of oncogenic bacteria in its development was first suggested in a case report from 1950s when a clinical association between Streptococcus bovis bacteraemia/endocarditis and carcinoma of the sigmoid was reported [6]. Since then, efforts have been made to explore the possible pathogens involved in CRC development. Multiple studies have demonstrated enrichment of fecal or tissue samples of CRC patients with specific bacterial pathogens, including
Fusobacterium spp. [7-9], Enterococcus faecalis (E.faecalis), [10], Enterotoxigenic Bacteroides fragilis (ETBF), Enteropathogenic Escherichia coli (EPEC) [11] and Streptococcus gallolyticus (S.gallolyticus) [12]. Recently, Nakatsu et al. suggested a taxonomically defined microbial consortium implicated in the development of CRC [13]. In addition, Ericsson et al. identified a naturally occurring variation in gut microbes associated with severity of colorectal cancer, as well as the abundance of certain taxa associated with decreased tumor burden [14]. Indeed, it seems that once the key players in the microbial dysbiosis associated with colorectal carcinogenesis are identified, this would probably result in new strategies in the diagnosis, treatment and even prevention of CRC.

Based on both in vitro and in vivo studies, oncogenic mechanisms of bacteria-driven $\mathrm{CRC}$ tumorigenesis include Wnt signaling activation (ETBF [15], EPEC [11], Fusobacterium [16]), pro-inflammatory signaling 
(E. faecalis $[17,18]$, S. gallolyticu $[19,20])$ and genotoxicity (EPEC [21], AIEC [22-24]).

To date, however, the presence of multiple CRCassociated bacteria have not been identified in populations of South China. And these types of studies were mostly performed in Western countries where the genetic and ethnic backgrounds of patients differ from those in Asian regions, which in turn may affect the composition of gut microbiota $[25,26]$. Furthermore, in these studies, pathogens, reported to be associated with CRC [27], have only been quantified in paired adenocarcinoma and adjacent normal mucosal samples, or fecal samples of CRC patients, without the comparison with the age- and sex-matched healthy control population. As samples in these studies were collected from patients already diagnosed with CRC, additional changes of gut microbiota might have occured. Those patients might be more susceptible to microflora colonization of normal colon epithelium - not only in existing cancer tissue, but also in the macroscopically normal adjacent tissue, which may indicate a pre-existing risk to bacteria colonization/ infection. For instance, 16SrDNA profile of colorectal cancer (CRC) paired tumor and normal biopsies has suggested that only $3 \%$ of biopsies from healthy controls contained any type of bacteria, while $\sim 90 \%$ patients with carcinomas or adenomas had $10^{3}-10^{5}$ microbiota in both macroscopically normal and malignant tissues [28].

In the present study, we applied quantitative real-time polymerase chain reaction (qPCR) to detect the presence of four pathogens (Fusobacterium spp., E.faecalis, ETBF and EPEC) in paired adenocarcinoma and adjacent normal mucosal samples, as well as in age- and sex-matched healthy controls in population of South China.

\section{RESULTS}

\section{Clinicopathological characterization of CRC patients}

The clinicopathological characteristics of the patients are summarized in Table 1. In brief, a total of 61 men and 36 women with a median age of 64.58 years (range, 31-92 years) were included in the study. The majority of cases were stage II or III cancers (64.94\%), while stage I and IV cancers accounted for $9.28 \%$ and $25.17 \%$, respectively. The cohort consisted of $64.95 \%$ rectal and $35.05 \%$ colon cancers, with moderately or well differentiated tumors accounting for $91.75 \%$ of analyzed samples.

\section{Fusobacterium spp., E.faecalis and Enterotoxigenic Bacteroides fragilis (ETBF) are significantly enriched in CRC tissues compared to the adjacent normal colon tissue}

In our study, CRC-associated bacteria were quantified in adenocarcinoma and adjacent normal mucous samples of the same patient by qPCR, using a serial dilution of genomic DNA of each bacterium as standard. As a result, varying levels of bacterial colonization in tumor and/or adjacent normal mucosa for all bacteria were detected. Of the bacteria that were examined, the median abundance of Fusobacterium spp. $(p<0.001$, Wilcoxon signed rank test), E.faecalis ( $p<0.05$, Wilcoxon signed rank test) and ETBF $(p<0.001$, Wilcoxon signed rank test) in CRC tissues was significantly higher than that in corresponding adjacent normal mucous tissue $(10 \mathrm{~cm}$ beyond cancer margins). The results of these analyses are summarized in Figure 1.

\section{Fusobacterium spp. and E.faecalis are increased in the adjacent normal mucous tissue of CRC patients compared to the healthy controls}

To determine whether CRC patients may be susceptible to CRC-associated bacteria colonization of the normally sterile colonic epithelium - the surrounding macroscopically normal tissue, we have examined the bacterial status of tumor tissue and adjacent normal mucous tissues of CRC patients as well as the bacterial status of age- and sex-matched healthy controls. Fusobacterium spp. $(p<0.05$, Kruskal-Wallis test followed by multiple comparisons) and E.faecalis ( $p<0.05$, Kruskal-Wallis test followed by multiple comparisons) were markedly enriched in the adjacent normal mucous tissue of CRC patients compared to healthy controls (Figure 2). No difference however was observed for EPEC $(p>0.05)$ between tumor tissues, adjacent normal tissues of CRC patients and healthy controls. E. faecalis was the most common bacteria detected, occurring in $95.88 \%(N=93)$ of tumors and $93.81 \%(N=91)$ of adjacent normal mucous tissues. The second most common bacteria detected in our study was Fusobacterium spp. which was detected in $72.16 \%(N=70)$ of tumors and $67.01 \%(N=65)$ of adjacent normal mucous tissues (Table 3). Combined E.faecalis and Fusobacterium spp. were detected in $70.10 \%(N=68)$ of tumor samples and $36.08 \%(N=35)$ of adjacent normal mucous tissues. The combination of all examined bacterial species was detected in $33.72 \%(N=29)$ of tumor tissues and $22.09 \%(N=19)$ of adjacent normal mucous tissues (Table 2).

\section{Clinicopathological features of CRC patients and their bacterial status}

Clinicopathological features of CRC patients and their association with the examined bacterial status are summarized in Table 3. No strongly significant association of four examined bacteria iwith CRC clinicopathologica lparameters e.g. tumor stage, location, infiltration depth and pathological differentiation were observed $(p>0.05)$. On the other hand an association between Fusobacterium spp. and B.faecalis in CRC samples was observed $(r=0.631, p=0.000)$ (Table 3). 


\begin{tabular}{ll}
\hline & CRC patients $(\boldsymbol{n}=\mathbf{9 7})$ \\
\hline Male/Female (n (\%)) & $61(62.89 \%) / 36(37.11 \%)$ \\
Age (Mean \pm SE) & $64.5773 \pm 1.1973$ \\
Tumor location (n (\%)) & $63(64.95 \%)$ \\
Colon cancer & $34(35.05 \%)$ \\
Rectal cancer & \\
Differentiation (n (\%)) & $8(8.25 \%)$ \\
Low differentiation & $89(91.75 \%)$ \\
Moderate-well differentiation & \\
TNM staging (n (\%)) & $16(16.49 \%)$ \\
T1 + T2 & $81(83.51 \%)$ \\
T3 + T4 & \\
Lymphatic metastasis (n (\%)) & $57(58.76 \%)$ \\
N0 & $40(41.24 \%)$ \\
N1 + N2 & \\
Metastasis (n (\%)) & $74(76.29 \%)$ \\
M0 & $23(23.71 \%)$ \\
M1 & \\
Dukes' classification (n (\%)) & $9(9.28 \%)$ \\
A & $26(26.80 \%)$ \\
B & $37(38.14 \%)$ \\
C & $25(25.78 \%)$ \\
D &
\end{tabular}
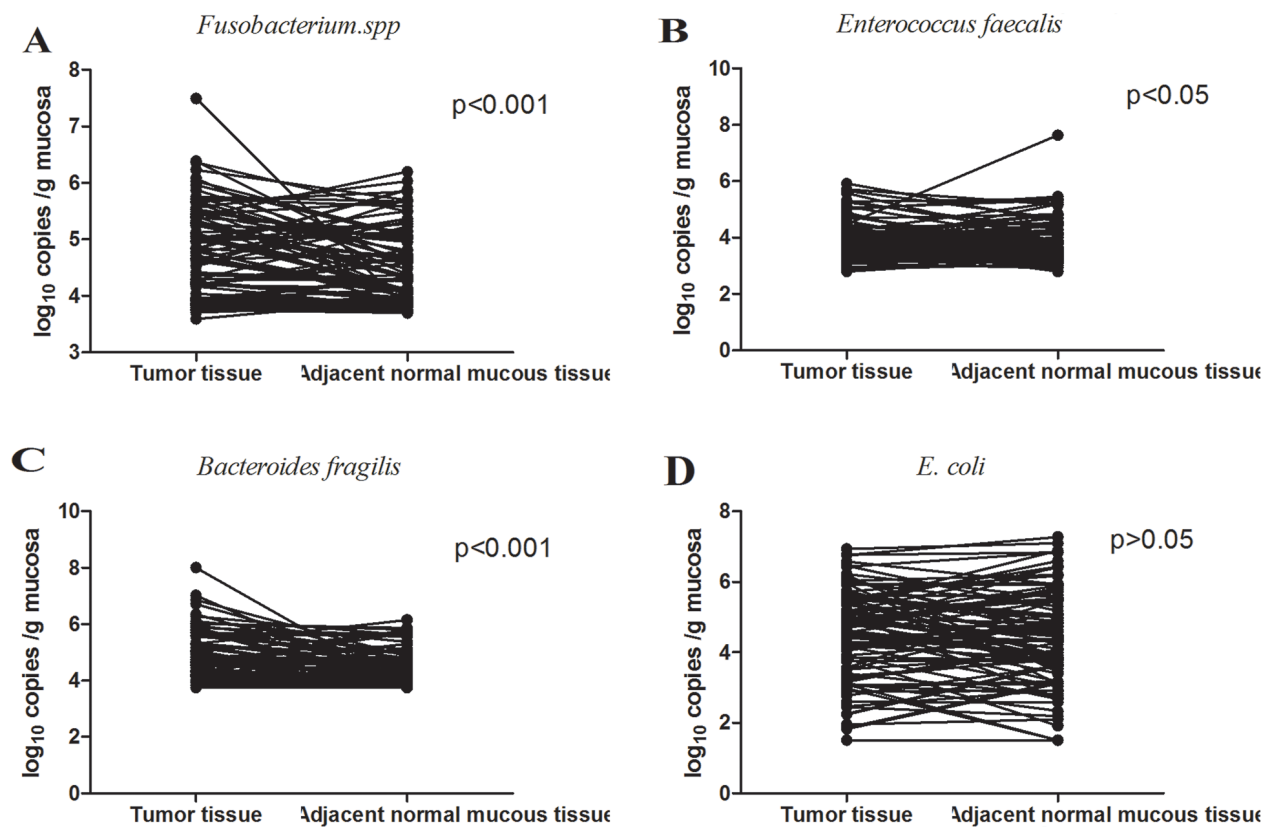

Figure 1: Quantitative real-time PCR analysis of bacteria in CRC tumor and corresponding normal mucous samples, presented as $\log 10$ copies/g mucosa of $50 \mathrm{ng}$ DNA. The median abundance of Fusobacterium spp. $(N=97, p<0.001$, Wilcoxon signed rank test), E.faecalis ( $N=97, p<0.05$, Wilcoxon signed rank test) and $\operatorname{ETBF}(N=87, p<0.001$, Wilcoxon signed rank test) in CRC tissues was significantly higher than that in adjacent normal mucous tissues ( $10 \mathrm{~cm}$ beyond cancer margins), while there was no significance in E.coli $(N=96, p>0.05$, Wilcoxon signed rank test) between CRC tissue and adjacent normal mucous tissue. 


\section{DISCUSSION}

It is known that bacterial dysbiosis contributes to a variety of colorectal diseases including CRC, but no specific bacterium was confirmed to be the key virulence factor [29-32]. Although the bacterial status of CRC patients previously has been explored before [27], the data on the CRC-associated microbes in Chinese CRC populations are scarce. Therefore, in order to gain a better understanding of bacterial colonization patterns in Chinese CRC patients in this study we have examined the presence of four CRC-associated bacteria across a single Chinese cohort in both tumor and histologically normal adjacent mucous tissue of CRC patients, as well as in age- and sexmatched healthy controls.

Notably, our finding that Fusobacterium spp., E.faecalis and Enterotoxigenic Bacteroides fragilis (ETBF) are significantly enriched in CRC tissues compared to the adjacent normal mucous tissues is consistent with previous studies [8, 27, 33]. Viljoen et al. [27] found a positive association between high-level colonization by Fusobacterium and regional lymph node metastases. In addition, in the same study the ETBF colonization and high-level of Fusobacterium colonization were associated with late-stage CRC, which we however did not observe in our present study. Colorectal cancer tissues provide rich nutrition surface and tumor-homing activity of certain microbiota has been reported in the literature [34]. Nevertheless, the microbiota presence does not necessarily suggest their oncogenic potential. Therefore, evaluating distribution of microflora in relation to lifestyle, ethnicity and clinicopathological factors may be essential in assessing the host-susceptibility to infection and putative bacteria-associated oncogenic mechanisms. In addition, microbiota abundance is not the only parameter that may be correlated with clinicopathological features of patients since even low-abundant microflora may exert significant effect on the host through toxins secretion. For instance, Dutilh et al. suggested that enterobacterial toxins were among the most highly detected in the meta transcriptomic
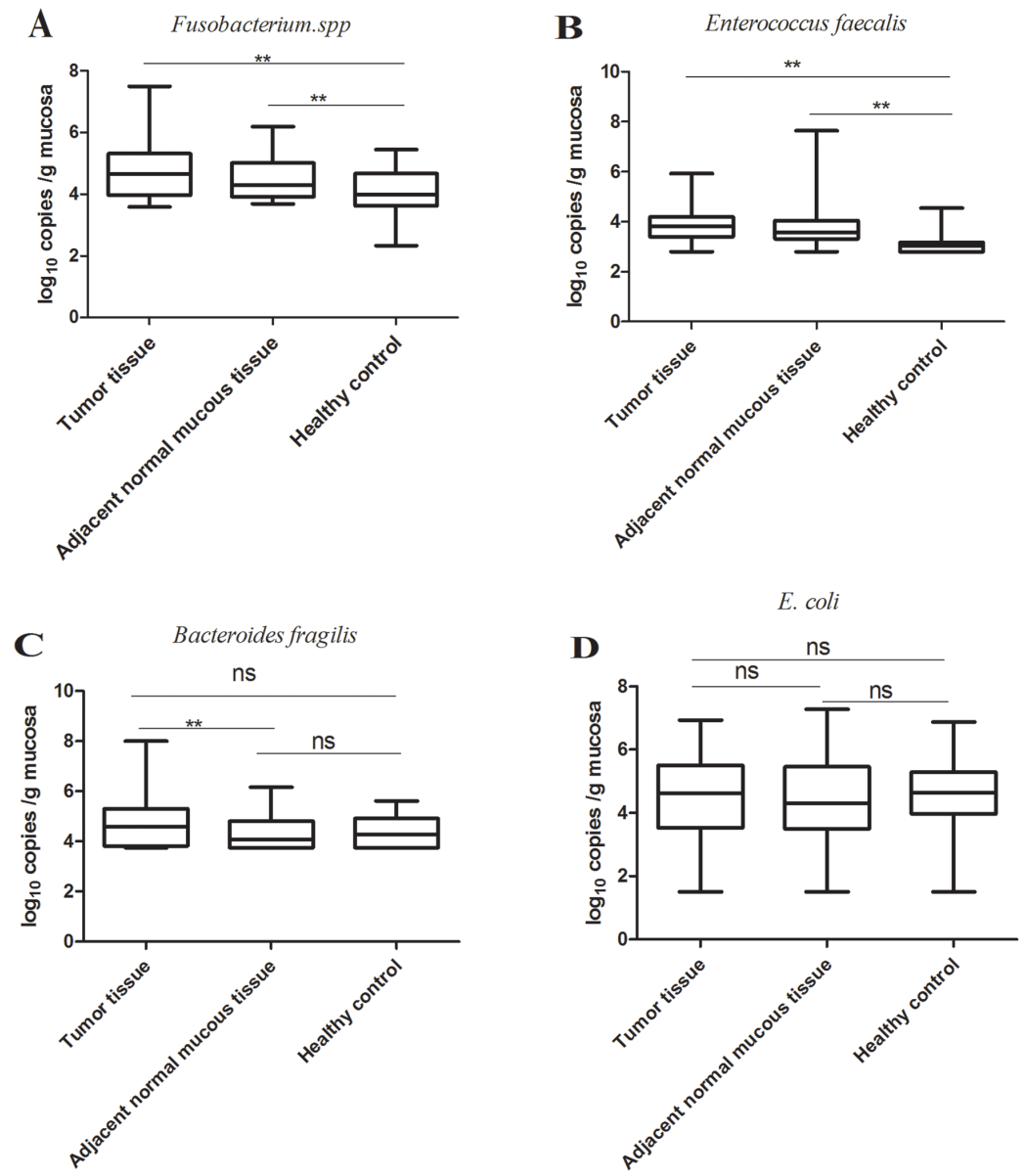

Figure 2: Quantification of bacteria in tumor tissues, adjacent normal mucous tissues of CRC patients and control tissues from age- and gender-matched healthy volunteers. Fusobacterium spp. $\left(\mathrm{N}_{\mathrm{CRC}}=97, \mathrm{~N}_{\mathrm{HC}}=48 ; p<0.05\right.$, Kruskal-Wallis test followed by multiple comparisons) and E. faecalis $\left(\mathrm{N}_{\mathrm{CRC}}=97, \mathrm{~N}_{\mathrm{HC}}=48 ; p<0.05\right.$, Kruskal-Wallis test followed by multiple comparisons) were markedly enriched in the matched adjacent normal mucous tissues compared to the healthy controls. No difference in $E$.coli $\left(\mathrm{N}_{\mathrm{CRC}}=96, \mathrm{~N}_{\mathrm{HC}}\right.$ $=48 ; p>0.05)$ and Bacteroides fragilis $\left(\mathrm{N}_{\mathrm{CRC}}=87, \mathrm{~N}_{\mathrm{HC}}=48 ; p>0.05\right)$ was observed between tumor tissues, corresponding adjacent normal mucous tissues and healthy controls. ${ }^{* *} p<0.05$; ns, no significance. $\mathrm{N}_{\mathrm{CRC}}$, the number of CRC patients; $\mathrm{N}_{\mathrm{HC}}$, the number of healthy controls. 
Table 2: Gut microbiota in tumor and adjacent normal tissue of CRC patients

\begin{tabular}{lcc}
\hline & Tumor tissue & Adjacent normal tissue \\
\hline Fusobacterium spp. & $70(72.16 \%)^{* *}$ & $65(67.01 \%)^{* *}$ \\
B.fragilis & $56(64.37 \%)$ & $40(45.98 \%)$ \\
E.faecalis & $93(95.88 \%)^{* *}$ & $91(93.81 \%)^{* *}$ \\
E. coli & $47(48.96 \%)$ & $40(41.67 \%)$ \\
Fusobacterium spp. + B.fragilis & $49(56.32 \%)$ & $32(36.78 \%)$ \\
Fusobacterium spp. + E.faecalis & $68(70.10 \%)^{* *}$ & $35(36.08 \%)$ \\
Fusobacterium spp. + E.coli & $36(37.50 \%)$ & $26(27.08 \%)$ \\
B.fragilis + E.faecalis & $55(63.22 \%)$ & $37(42.53 \%)$ \\
B.fragilis + E.coli & $35(40.70 \%)$ & $24(27.91 \%)$ \\
E.faecalis + E.coli & $46(47.92 \%)$ & $39(40.63 \%)$ \\
Fusobacterium spp. + B.fragilis + E.faecalis & $47(54.02 \%)$ & $29(33.33 \%)$ \\
Fusobacterium spp. + B.fragilis + E.coli & $30(34.88 \%)$ & $20(23.26 \%)$ \\
B.fragilis + E.faecalis + E.coli & $34(39.53 \%)$ & $23(26.74 \%)$ \\
Fusobacterium spp. + B.fragilis + & $29(33.72 \%)$ & $19(22.09 \%)$ \\
E.faecalis + E.coli & & \\
\hline
\end{tabular}

**high abundance in CRC.

sequencing data of CRC tumors and matched adjacent normal samples [35]. Indeed, antigens and metabolites produced by gut microbiota may have important roles in affecting CRC risk through their interactions with host immunity andmetabolism [36, 37]. The observed changes in bacterial mocrobiome might contribute to the further progression of CRC through the various possible mechanisms. In addition, it is possible that changes of gut microbiota identified in the present study might be a consequence of CRC.

In our study a group consisting of healthy controls was included in order to obtain punch biopsies of normal mucosal tissues and to compare them with the normal mucous tissues in the proximity of the tumors of CRC patients. In our study, Fusobacterium spp. and E.faecalis were increased in the adjacent normal mucous tissues of CRC patients compared to the healthy controls. These findings may be an additional supporting evidence for the hypothesis of the possible association of Fusobacterium spp. and E.faecalis with the transformation of colorectal mucosa from early adenomatous polyp stages to late CRC stages. In fact, it is possible that increase in Fusobacterium spp. and E.faecalis might be an earlier event than adenoma. However, this hypothesis needs a prospective study to determine the possible association of mentioned benign colorectal lesions with the increase in Fusobacterium spp. and E.faecalis presence.

There are some limitations to our study. First, due to the study design it is impossible to untangle the causal relationship between gut microflora and CRC. As samples were collected from patients already diagnosed with CRC, whether Fusobacterium spp. or E.faecalisis a cause or a consequence of CRC is not clear. Second, the sample size included in this study was rather small. In addition, clinicopathological features such as stage of disease [27], tumor location [27], age [27], lymph node metastases $[7,38]$ which have been previously reported to be associated with high-level colonization by Fusobacterium in patients with CRC were not observed in our study. Due to the lack of data on follow-up, we could not evaluate these bacteria in association with a longer time-torelapse. In this study, we have examined the presence of four pathogens in tissue samples of CRC patients not in fecal samples. Indeed, adherent microflora might have a greater influence on gene expression in the colonic mucosal cells than transient microbiota that are flushed in faecal samples. Nevertheless. Larger studies of faecal and colonic tissue samples from different stages of CRC are necessary to determine possible bacterial biomarkers of oncogenic transformation.

\section{MATERIALS AND METHODS}

\section{Patients}

In this study, 97 patients with pathologically confirmed colorectal adenocarcinoma who underwent the surgical resection at the Department of General Surgery of Guangzhou First People's hospital between November 2012 and November 2014 were recruited. The medical history of recruited patients was evaluated and no one had history of gastrointestinal disease, ulceration or other disease that might affect gut microbiota. Dietary preferences and antibiotic usage (in the last four weeks) of enrolled subjects 
Table 3: Correlation between bacterial population and clinicopathological parameters

\begin{tabular}{lcccccccc}
\hline Spearman's rho & \multicolumn{2}{c}{$\begin{array}{c}\text { Fusobacteriumspp. } \\
(\mathbf{r}, \mathbf{p})\end{array}$} & \multicolumn{2}{c}{$\begin{array}{c}\text { B.fragilis } \\
(\mathbf{r}, \mathbf{p})\end{array}$} & \multicolumn{2}{c}{$\begin{array}{c}\text { E.faecalis } \\
(\mathbf{r}, \mathbf{p})\end{array}$} & \multicolumn{2}{c}{$\begin{array}{c}\text { E.coli } \\
(\mathbf{r}, \mathbf{p})\end{array}$} \\
\hline Tumor location & -0.12 & 0.243 & -0.166 & 0.117 & -0.062 & 0.546 & -0.256 & 0.012 \\
Tumor differitation & 0.078 & 0.452 & 0.073 & 0.496 & 0.041 & 0.69 & 0.006 & 0.957 \\
Tumor infiltration & -0.06 & 0.561 & -0.108 & 0.302 & -0.163 & 0.144 & -0.015 & 0.887 \\
Lymphatic metastasis & -0.02 & 0.847 & -0.03 & 0.778 & -0.19 & 0.064 & -0.14 & 0.177 \\
metastasis & 0.049 & 0.631 & 0.04 & 0.708 & -0.233 & 0.022 & -0.219 & 0.032 \\
Duke's stage & -0.108 & 0.294 & -0.078 & 0.468 & -0.192 & 0.061 & -0.145 & 0.162 \\
Tissue CEA & -0.252 & 0.043 & -0.162 & 0.216 & 0.028 & 0.825 & 0.078 & 0.542 \\
Tissue P53 & -0.156 & 0.15 & -0.075 & 0.512 & 0.074 & 0.500 & 0.017 & 0.879 \\
Tissue Villin & -0.073 & 0.522 & -0.121 & 0.307 & 0.047 & 0.68 & 0.046 & 0.685 \\
Tissue EGFR & -0.107 & 0.415 & -0.136 & 0.322 & -0.005 & 0.967 & 0.163 & 0.212 \\
Tissue Ki67 & -0.037 & 0.73 & -0.113 & 0.309 & 0.071 & 0.505 & 0.067 & 0.535 \\
Serum CEA & 0.109 & 0.303 & 0.194 & 0.076 & 0.112 & 0.286 & -0.049 & 0.642 \\
Serum CA199 & 0.013 & 0.900 & 0.000 & 0.999 & -0.018 & 0.868 & -0.204 & 0.550 \\
Serum CRP & 0.03 & 0.786 & 0.09 & 0.434 & 0.261 & 0.016 & -0.082 & 0.461 \\
B.fragilis & 0.631 & $0.000 * *$ & & & 0.2 & 0.054 & 0.347 & $0.01 * *$ \\
E.faecalis & 0.067 & 0.508 & 0.02 & 0.54 & & & 0.257 & $0.01 * *$ \\
E. coli & 0.199 & 0.048 & 0.347 & $0.001 * *$ & 0.257 & $0.010 * *$ & & \\
\hline **p $<0.05$. & & & & & & &
\end{tabular}

were recorded to role out diet habit bias or antibiotic usage that may influence the bacterial microbiome. Fresh CRC and adjacent non-tumor tissues $(10 \mathrm{~cm}$ beyond cancer margins) from each subject were collected. In addition, 48 age- and sex- matched control subjects were recruited. They were referred to hospital for colonoscopy for various reasons and no gastrointestinal disease or history of gastrointestinal diseases and ulcerations were reported and normal colonic mucosa was confirmed. Colonoscopy biopsy was taken from control subjects to compare their level of microbes with those in CRC tissues and adjacent normal tissues taken from the same patient.

Samples were snap frozen in liquid nitrogen and then stored at $-80^{\circ} \mathrm{C}$ until use. The CRC stages were assigned according to TNM and Dukes grades [39]. All participants were local residents of Guangzhou city for more than 10 years.

All study protocols were in compliance with the Declaration of Helsinki and were approved by the Ethics Committee of Guangzhou First People's Hospital affiliated with Guangzhou Medical University. Informed consent was obtained from all subjects. All experiments were performed in accordance with relevant guidelines and regulations.

\section{DNA isolation and quantitative real- time PCR (qPCR)}

Total DNA was isolated from samples using QIAamp DNA Mini Kit (QIAGEN, Hilden, Germany) according to the manufacturer's instructions. All DNA samples were stored at $-80^{\circ} \mathrm{C}$ until further processing.

Primer pairs targeted to detect 16 S ribosomal RNA gene of four bacterial groups or species included in this study (Fusobacterium spp., E.faecalis, ETBF and EPEC) are listed in Table 4. The 16S rRNA gene of each bacterial strain was cloned into the pUCm-T vector (Sangon, Shanghai, China) according to the manufacturer's protocol and was used as a copy number standard. For each realtime PCR standard, copy number concentration was calculated, based on the length of the PCR product and the mass concentration. The standards were stored at $-80^{\circ} \mathrm{C}$, and serial dilutions ( 1 to $10^{8}$ copies $/ \mu \mathrm{L}$ ) were made prior to each real-time PCR assay. The results of qPCR for each sample were expressed as the copy number of bacterial 16S ribosomal DNA per gram of tissue. Real-time PCR assays were performed in 96-well optical plates using the LightCycler ${ }^{\circledR} 480$ Real-Time PCR System (Roche Diagnostics, Rotkreuz, Switzerland). All assays were carried out in duplicate and performed in a total volume of $20 \mu 1$ with LightCycler ${ }^{\circledR} 480$ SYBR Green I Master solution (Roche Diagnostics, Mannheim, Germany). The reaction mixture consisted of $0.5 \mu \mathrm{M}$ of each of the specific primer pairs and $5 \mu \mathrm{l}$ of DNA template. Amplifications were performed as follows: initial denaturation at $95^{\circ} \mathrm{C}$ for $5 \mathrm{~min}$, followed by 45 cycles of denaturation at $95^{\circ} \mathrm{C}$ for $10 \mathrm{~s}$, annealing at $52-56^{\circ} \mathrm{C}$ (primer dependent) for $10 \mathrm{~s}$, and extension at $72^{\circ} \mathrm{C}$ for $10 \mathrm{~s}$. Specificity of each amplification was assessed by melting curve analysis of 
Table 4: Primers for the detection of specific bacterial pathogens by quantitative real-time PCR

\begin{tabular}{llcc}
\hline Target bacteria & Primer Sequence $\left(\mathbf{5}^{\prime}\right.$ to $\mathbf{3}^{\prime}$ ) & Annealing Temp $\left({ }^{\circ} \mathbf{C}\right)$ & Product Size (bp) \\
\hline Fusobacterium spp. $[40]$ & $\begin{array}{l}\text { F: GGATTTATTGGGCGTAAAGC } \\
\text { R:GGCATTCCTACAAATATCTACGAA }\end{array}$ & 55 & 162 \\
Enterococcus faecalis $[41]$ & $\begin{array}{l}\text { F: CCCTTATTGTTAGTTGCCATCATT } \\
\text { R: ACTCGTTGTACTTCCCATTGT }\end{array}$ & 55 & 144 \\
B. fragilis $[42]$ & F: ATAGCCTTTCGAAAGRAAGAT & 52 & 501 \\
& R: CCAGTATCAACTGCAATTTTA & & \\
E. coli $[43]$ & $\begin{array}{l}5 \\
\text { F:GTTAATACCTTTGCTCATTGA }\end{array}$ & 56 & 340
\end{tabular}

the amplified PCR product. The efficiency of amplification for each primer pair was estimated from the standard curves.

\section{Assessment of clinical parameters}

Clinical parameters of CRC patients included in this study were collected according to medical history and medical records of hospital patients. The collected data included patients' gender, age, serological examinations such as serum CEA, CA199, C-reaction protein (CRP), and pathohistological biopsy immunohistochemical results for tissue CEA, P53, Villin, Epidermal Growth Factor Receptor (EGFR) and Ki67.

\section{Statistical analysis}

All data are presented as means \pm standard error mean (SEM) for quantitative variables and as frequencies for qualitative variables. Given the non-normal distribution of the data analyzed, the nonparametric test was used to examine changes in bacterial number. In order to assess quantitative differences between paired tumor and adjacent non-tumor samples for each bacterium, we used the Wilcoxon signed rank test and applied it to the subset of samples. For the comparison among healthy control, adjacent tissue and cancer tissue groups, Kruskal-Wallis test was applied. The Spearman correlation coefficient was calculated to estimate the linear correlations between variables. Statistical analyses were performed with the statistical software package SPSS16.0 (SPSS Inc., Chicago, IL, USA). Two-tailed $P$ value less than 0.05 was considered statistically significant.

\section{ACKNOWLEDGMENTS AND FUNDING}

The work was funded by the National Clinical Key Institute Foundation of Chinese Health and Family Planning Ministry (Grant No. 2013-544).

\section{CONFLICTS OF INTEREST}

None declared.

\section{FINANCIAL SUPPORT}

The authors declare no competing financial interests.

\section{REFERENCES}

1. Schiffman M, Castle PE, Jeronimo J, Rodriguez AC, Wacholder S. Human papillomavirus and cervical cancer. Lancet. 2007; 370:890-907. doi: 10.1016/S01406736(07)61416-0.

2. Machado AM, Figueiredo C, Seruca R, Rasmussen LJ. Helicobacter pylori infection generates genetic instability in gastric cells. Biochim Biophys Acta. 2010; 1806:58-65. doi: 10.1016/j.bbcan.2010.01.007.

3. Di Bisceglie AM, Goodman ZD, Ishak KG, Hoofnagle JH, Melpolder JJ, Alter HJ. Long-term clinical and histopathological follow-up of chronic posttransfusion hepatitis. Hepatology. 1991; 14:969-74. doi:

4. Kiyosawa K, Sodeyama T, Tanaka E, Gibo Y, Yoshizawa K, Nakano Y, Furuta S, Akahane Y, Nishioka K, Purcell RH, et al. Interrelationship of blood transfusion, non-A, non-B hepatitis and hepatocellular carcinoma: analysis by detection of antibody to hepatitis $\mathrm{C}$ virus. Hepatology. 1990; 12:671-5.

5. Jemal A, Bray F, Center MM, Ferlay J, Ward E, Forman D. Global cancer statistics. CA Cancer J Clin. 2011; 61:69-90. doi: 10.3322/caac.20107.

6. Mc CW, Mason JM, 3rd. Enterococcal endocarditis associated with carcinoma of the sigmoid; report of a case. J Med Assoc State Ala. 1951; 21:162-6.

7. Castellarin M, Warren RL, Freeman JD, Dreolini L, Krzywinski M, Strauss J, Barnes R, Watson P, AllenVercoe E, Moore RA, Holt RA. Fusobacterium nucleatum infection is prevalent in human colorectal carcinoma. Genome Res. 2012; 22:299-306. doi: 10.1101/ gr.126516.111. 
8. McCoy AN, Araujo-Perez F, Azcarate-Peril A, Yeh JJ, Sandler RS, Keku TO. Fusobacterium is associated with colorectal adenomas. PLoS One. 2013; 8:e53653. doi: 10.1371/journal.pone.0053653.

9. Kostic AD, Gevers D, Pedamallu CS, Michaud M, Duke F, Earl AM, Ojesina AI, Jung J, Bass AJ, Tabernero J, Baselga J, Liu C, Shivdasani RA, et al. Genomic analysis identifies association of Fusobacterium with colorectal carcinoma. Genome Res. 2012; 22:292-8. doi: 10.1101/gr.126573.111.

10. Balamurugan R, Rajendiran E, George S, Samuel GV, Ramakrishna BS. Real-time polymerase chain reaction quantification of specific butyrate-producing bacteria, Desulfovibrio and Enterococcus faecalis in the feces of patients with colorectal cancer. J Gastroenterol Hepatol. 2008; 23:1298-303. doi: 10.1111/j.1440-1746.2008.05490.x.

11. Umar S, Wang Y, Morris AP, Sellin JH. Dual alterations in casein kinase I-epsilon and GSK-3beta modulate betacatenin stability in hyperproliferating colonic epithelia. Am J Physiol Gastrointest Liver Physiol. 2007; 292:G599-607. doi: 10.1152/ajpgi.00343.2006.

12. Abdulamir AS, Hafidh RR, Bakar FA. Molecular detection, quantification, and isolation of Streptococcus gallolyticus bacteria colonizing colorectal tumors: inflammation-driven potential of carcinogenesis via IL-1, COX-2, and IL-8. Mol Cancer. 2010; 9:249. doi: 10.1186/1476-4598-9-249.

13. Nakatsu G, Li X, Zhou H, Sheng J, Wong SH, Wu WK, Ng SC, Tsoi H, Dong Y, Zhang N, He Y, Kang Q, Cao L, et al. Gut mucosal microbiome across stages of colorectal carcinogenesis. Nat Commun. 2015; 6:8727. doi: 10.1038/ ncomms9727.

14. Ericsson AC, Akter S, Hanson MM, Busi SB, Parker TW, Schehr RJ, Hankins MA, Ahner CE, Davis JW, Franklin CL, Amos-Landgraf JM, Bryda EC. Differential susceptibility to colorectal cancer due to naturally occurring gut microbiota. Oncotarget. 2015; 6:33689-704. doi: 10.18632/ oncotarget.5604.

15. Wu S, Morin PJ, Maouyo D, Sears CL. Bacteroides fragilis enterotoxin induces c-Myc expression and cellular proliferation. Gastroenterology. 2003; 124:392-400. doi: 10.1053/gast.2003.50047.

16. Rubinstein MR, Wang X, Liu W, Hao Y, Cai G, Han YW. Fusobacterium nucleatum promotes colorectal carcinogenesis by modulating E-cadherin/beta-catenin signaling via its FadA adhesin. Cell Host Microbe. 2013; 14:195-206. doi: 10.1016/j.chom.2013.07.012.

17. Balish E, Warner T. Enterococcus faecalis induces inflammatory bowel disease in interleukin-10 knockout mice. Am J Pathol. 2002; 160:2253-7. doi: 10.1016/S00029440(10)61172-8.

18. Kim SC, Tonkonogy SL, Albright CA, Tsang J, Balish EJ, Braun J, Huycke MM, Sartor RB. Variable phenotypes of enterocolitis in interleukin 10-deficient mice monoassociated with two different commensal bacteria. Gastroenterology. 2005; 128:891-906. doi:

19. Ellmerich S, Scholler M, Duranton B, Gosse F, Galluser M, Klein JP, Raul F. Promotion of intestinal carcinogenesis by Streptococcus bovis. Carcinogenesis. 2000; 21:753-6. doi:
20. Biarc J, Nguyen IS, Pini A, Gosse F, Richert S, Thierse D, Van Dorsselaer A, Leize-Wagner E, Raul F, Klein JP, Scholler-Guinard M. Carcinogenic properties of proteins with pro-inflammatory activity from Streptococcus infantarius (formerly S.bovis). Carcinogenesis. 2004; 25:1477-84. doi: 10.1093/carcin/bgh091.

21. Maddocks OD, Scanlon KM, Donnenberg MS. An Escherichia coli effector protein promotes host mutation via depletion of DNA mismatch repair proteins. MBio. 2013; 4:e00152-13. doi: 10.1128/mBio.00152-13.

22. Prorok-Hamon M, Friswell MK, Alswied A, Roberts CL, Song F, Flanagan PK, Knight P, Codling C, Marchesi JR, Winstanley C, Hall N, Rhodes JM, Campbell BJ. Colonic mucosa-associated diffusely adherent afaC + Escherichia coli expressing lpfA and pks are increased in inflammatory bowel disease and colon cancer. Gut. 2014; 63:761-70. doi: 10.1136/gutjnl-2013-304739.

23. Buc E, Dubois D, Sauvanet P, Raisch J, Delmas J, Darfeuille-Michaud A, Pezet D, Bonnet R. High prevalence of mucosa-associated E. coli producing cyclomodulin and genotoxin in colon cancer. PLoS One. 2013; 8:e56964. doi: 10.1371/journal.pone.0056964.

24. Cuevas-Ramos G, Petit CR, Marcq I, Boury M, Oswald E, Nougayrede JP. Escherichia coli induces DNA damage in vivo and triggers genomic instability in mammalian cells. Proc Natl Acad Sci U S A. 2010; 107:11537-42. doi: 10.1073/pnas.1001261107.

25. Suzuki TA, Worobey M. Geographical variation of human gut microbial composition. Biol Lett. 2014; 10:20131037. doi: 10.1098/rsbl.2013.1037.

26. Ishikawa E, Matsuki T, Kubota H, Makino H, Sakai T, Oishi K, Kushiro A, Fujimoto J, Watanabe K, Watanuki M, Tanaka R. Ethnic diversity of gut microbiota: species characterization of Bacteroides fragilis group and genus Bifidobacterium in healthy Belgian adults, and comparison with data from Japanese subjects. J Biosci Bioeng. 2013; 116:265-70. doi: 10.1016/j.jbiosc.2013.02.010.

27. Viljoen KS, Dakshinamurthy A, Goldberg P, Blackburn JM. Quantitative profiling of colorectal cancer-associated bacteria reveals associations between fusobacterium spp., enterotoxigenic Bacteroides fragilis (ETBF) and clinicopathological features of colorectal cancer. PLoS One. 2015; 10:e0119462. doi: 10.1371/journal.pone.0119462.

28. Swidsinski A, Khilkin M, Kerjaschki D, Schreiber S, Ortner M, Weber J, Lochs H. Association between intraepithelial Escherichia coli and colorectal cancer. Gastroenterology. 1998; 115:281-6. doi:

29. Tremaroli V, Backhed F. Functional interactions between the gut microbiota and host metabolism. Nature. 2012; 489:242-9. doi: 10.1038/nature11552.

30. Sekirov I, Russell SL, Antunes LC, Finlay BB. Gut microbiota in health and disease. Physiol Rev. 2010; 90:859-904. doi: 10.1152/physrev.00045.2009.

31. Bustos Fernandez LM, Lasa JS, Man F. Intestinal microbiota: its role in digestive diseases. J Clin Gastroenterol. 2014; 48:657-66. doi: 10.1097/MCG.0000000000000153. 
32. Allen-Vercoe E, Jobin C. Fusobacterium and Enterobacteriaceae: important players for CRC? Immunol Lett. 2014; 162:54-61. doi: 10.1016/j.imlet.2014.05.014.

33. Keku TO, McCoy AN, Azcarate-Peril AM. Fusobacterium spp. and colorectal cancer: cause or consequence? Trends Microbiol. 2013; 21:506-8. doi: 10.1016/j.tim.2013.08.004.

34. Cummins J, Tangney M. Bacteria and tumours: causative agents or opportunistic inhabitants? Infect Agent Cancer. 2013; 8:11. doi: 10.1186/1750-9378-8-11.

35. Dutilh BE, Backus L, van Hijum SA, Tjalsma H. Screening metatranscriptomes for toxin genes as functional drivers of human colorectal cancer. Best Pract Res Clin Gastroenterol. 2013; 27:85-99. doi: 10.1016/j.bpg.2013.03.008.

36. Davis CD, Milner JA. Gastrointestinal microflora, food components and colon cancer prevention. J Nutr Biochem. 2009; 20:743-52. doi: 10.1016/j.jnutbio.2009.06.001.

37. Saleh M, Trinchieri G. Innate immune mechanisms of colitis and colitis-associated colorectal cancer. Nat Rev Immunol. 2011; 11:9-20. doi: 10.1038/nri2891.

38. Tahara T, Yamamoto E, Suzuki H, Maruyama R, Chung W, Garriga J, Jelinek J, Yamano HO, Sugai T, An B, Shureiqi I, Toyota M, Kondo Y, et al. Fusobacterium in colonic flora and molecular features of colorectal carcinoma. Cancer Res. 2014; 74:1311-8. doi: 10.1158/0008-5472.CAN-13-1865.

39. Williams ST, Beart RW, Jr. Staging of colorectal cancer. Semin Surg Oncol. 1992; 8:89-93. doi:
40. Boutaga K, van Winkelhoff AJ, Vandenbroucke-Grauls CM, Savelkoul PH. Periodontal pathogens: a quantitative comparison of anaerobic culture and real-time PCR. FEMS Immunol Med Microbiol. 2005; 45:191-9. doi: 10.1016/j. femsim.2005.03.011.

41. Rinttila T, Kassinen A, Malinen E, Krogius L, Palva A. Development of an extensive set of 16S rDNA-targeted primers for quantification of pathogenic and indigenous bacteria in faecal samples by real-time PCR. J Appl Microbiol. 2004; 97:1166-77. doi: 10.1111/j.13652672.2004.02409.x.

42. Shiryaev SA, Remacle AG, Chernov AV, Golubkov VS, Motamedchaboki K, Muranaka N, Dambacher CM, Capek P, Kukreja M, Kozlov IA, Perucho M, Cieplak P, Strongin AY. Substrate cleavage profiling suggests a distinct function of Bacteroides fragilis metalloproteinases (fragilysin and metalloproteinase II) at the microbiomeinflammation-cancer interface. J Biol Chem. 2013; 288:34956-67. doi: 10.1074/jbc.M113.516153.

43. Malinen E, Kassinen A, Rinttila T, Palva A. Comparison of real-time PCR with SYBR Green I or 5'-nuclease assays and dot-blot hybridization with rDNA-targeted oligonucleotide probes in quantification of selected faecal bacteria. Microbiology. 2003; 149:269-77. doi: 10.1099/ mic.0.25975-0. 